\title{
Removal of cadmium (II) from aqueous effluents by sorption on Romanian silver fir tree bark (Abies alba Mill.) wastes
}

\author{
Tofan L. ${ }^{1}$, Paduraru C. ${ }^{1,}$, Bunia I. ${ }^{2}$, Mihailescu Amalinei R.L. ${ }^{3}$ and Miron A. ${ }^{3}$ \\ 1"Gheorghe Asachi" Technical University of lasi, Environmental Engineering and Management Department, 71A D. Mangeron Street, \\ 700050 lasi, Romania; \\ 2"Petru Poni" Institute of Macromolecular Chemistry, 41A Grigore Ghica Voda Street, 700487 lassy, Romania \\ 3"Gr. T. Popa" University of Medicine and Pharmacy, Department of Pharmacognosy, School of Pharmacy Universitatii Str. 16, 700115 \\ Iasi, Romania
}

Received: 09/03/2016, Accepted: 07/03/2017, Available online: 09/03/2017

*to whom all correspondence should be addressed:

e-mail: cpadur2005@yahoo.com

\begin{abstract}
In last decades the search for new low cost sorbents that have heavy metal ions binding capabilities is a hot topic in the field of clean-up technologies. In this study, wastes of Romanian silver tree (Abies alba) bark were explored for first time as green and economical sorbent for the removal of $\mathrm{Cd}(\mathrm{II})$ ions from aqueous solutions. The effect of various experimental parameters such as initial solution $\mathrm{pH}$, sorbent dose, initial $\mathrm{Cd}$ (II) concentration, temperature and contact time has been investigated under batch conditions.

The Langmuir and Freundlich models were used to describe the equilibrium isotherms and both models have been fitted very well. According to the evaluation using the Langmuir equation, the maximum sorption capacity of $\mathrm{Cd}$ (II) ions on Abies alba bark waste was found to be 11.98 $\mathrm{mg} \mathrm{g}^{-1}$ at $293 \mathrm{~K}$. The thermodynamic parameters showed that the process of $\mathrm{Cd}$ (II) sorption on silver fir tree bark was feasible, spontaneous and endothermic. Kinetic data were properly fitted with the pseudo-second order model. The obtained results strongly suggest that Romanian silver tree (Abies alba) bark is eligible as an efficient sorbent for the decontamination of toxic metals from wastewaters.
\end{abstract}

Keywords: bark; cadmium; sorbent; isotherm; kinetic; thermodynamic.

\section{Introduction}

The population dynamics, rapid urbanization and nonuniform distribution of urban areas, the economy development associated with energy use and waste generation from domestic and industrial sources have considerably enhanced the release of heavy metals into the environment. The impacts of these metals on the ecosystems and on humans are relevant from the economic, environmental and public health point of view. According to a ranking of metal interest priorities, cadmium is of the tree most interesting heavy metals for removal and/or recovery considering the combination of environmental risk and reserve depletion (Volensky, 2001).

Sorption has evolved into one of the most effective processes of cadmium removal/recovery, due to its advantages such as: high removal efficiencies, applicability for various concentrations, lack of sludge production, sorbent versatility, etc. (Rao et al., 2010; Purkaystha et al., 2014; Ghosh et al., 2015). However, the removal efficiencies of cadmium by sorption, depend on several factors such as: initial loads of cadmium in the influent, purpose of treatment (drinking/industrial water production, wastewater treatment for disposal or recycling), costs of the overall process, properties and conditions for regeneration of the sorbent materials (Teodosiu et al., 2014). In this context, the use of natural and waste materials that are biodegradable, readily available at little or no cost in place of conventional sorbents is in conformity with green chemistry and green environment, now in the front burn of global environmental issues (Okoro and Okoro, 2011; Salman et al., 2016).

The use of different tree barks as heavy metal ion sorbents is of a special interest since they have significant sorption capacities even at low metal concentration, are abundant, renewable and low-cost, have reductive abilities, providing versatile applications in heavy metal effluent management (Al-Asheh and Duvnjak, 1997; Aoyama et al., 2004; Escudero et al., 2008; Gondogdu et al., 2009; Jauberty et al., 2011; Amalinei et al., 2012; Tofan et al., 2012; Sen et al., 2015).

The silver fir tree (Abies alba Mill.) is a coniferous species in the family of Pinaceae that is widely spread across Europe. In Romania it grows naturally in the Carpathian Mountains, but it is also planted due to its economic, environmental and social importance The silver fir tree occupies $5 \%$ of the Romanian forest area, being the second coniferous tree, as percentage, after spruce. The wood of 
mature Abies alba Mill. tree is used in construction and furniture industries, the bark being the main waste product.

Previous studies have been emphasized that Romanian silver fir cone powder and sawdust (Abies alba) are able to retain cadmium(II) ions from aqueous solutions, the maximum sorption capacity having low values of 3.74 $\mathrm{mg} \mathrm{Cd} \mathrm{g}^{-1}$ of cone powder and $2.159 \mathrm{mg} \mathrm{Cd} \mathrm{g}^{-1}$ of sawdust, respectively (Manzatu et al., 2014; Nagy et al.,2013). But among tree biomass components, bark has the highest capacity for heavy metal sorption, followed by cones, needles and wood (Sen et al., 2015). Despite the large amounts of silver fir bark wastes generated in Romania from the industrial processing of the silver fir wood, no studies on the sorption capabilities of Romanian Abies alba bark have been carried out.

Against this background, the aim of the present work is to investigate the possibility of conversion of Romanian silver fir tree bark residues into a low-cost sorbent for the removal of $\mathrm{Cd}$ (II) ions from aqueous solutions.

\section{Experimental}

\subsection{Plant Material}

Patches of Abies alba Mill bark were collected in the Calimani Mountains (Romania) in March 2008. A full-grown tree was randomly selected for collection. The species was identified and authenticated by specialists from Botanical Garden, lasi, Romania. The bark was shade-dried at room temperature for two weeks and powdered in a knife mill. A voucher sample was deposited in the Department of Pharmacognosy, Faculty of Pharmacy, "Gr. T. Popa" University of Medicine and Pharmacy, Iasi, Romania. Before use, the natural material was washed with deionized water several times and then dried at $40{ }^{\circ} \mathrm{C}$ for $24 \mathrm{~h}$.

\subsection{Chemicals}

Stock solution of $1200 \mathrm{mg} \mathrm{l}^{-1}$ was prepared by dissolution of analytical grade reagent $\mathrm{CdSO}_{4} \cdot 8 \mathrm{H}_{2} \mathrm{O}$ (Sigma-Aldrich) in deionised water and was complexonometrically standardized. Working solutions of $\mathrm{Cd}$ (II) were prepared by the appropriate dilutions of the stock solution.

In order to study the effect of medium acidity on the sorption process, a solution of $\mathrm{H}_{2} \mathrm{SO}_{4}$ with concentration of $10^{-2} \mathrm{~mol} \mathrm{I}^{-1}$ has been used (340-A /SET $1 \mathrm{pH}$-meter).

\subsection{Sorption procedure}

Table 1. Sorption experimental conditions

\begin{tabular}{cccccc}
\hline Nature of investigation & Initial pH & $\begin{array}{c}\text { Bark dose } \\
\left(\mathrm{g} \mathrm{l}^{-1}\right)\end{array}$ & $\begin{array}{c}\text { Metal ion concentration } \\
\left(\mathbf{m g ~ l}^{-1}\right)\end{array}$ & Temperature $\left({ }^{\circ} \mathrm{C}\right)$ & $\begin{array}{c}\text { Contact time } \\
(\mathbf{h})\end{array}$ \\
\hline Solution pH effect & $1-5$ & 3 & 72.00 & $20 \pm 2$ & 8 \\
\hline Bark dose effect & $4.5-5$ & $2-30$ & 72.00 & $20 \pm 2$ & 8 \\
\hline $\begin{array}{c}\text { Initial concentration } \\
\text { effect }\end{array}$ & $4.5-5$ & 3 & $22-192$ & $4 ; 20 ; 60$ & 8 \\
\hline Temperature effect & $4.5-5$ & 3 & $22-192$ & $4 ; 20 ; 60$ & 24 \\
\hline Effect of contact time & $4.5-5$ & 3 & $\begin{array}{c}72.00 \\
144.00\end{array}$ & $20 \pm 2$ & $0.25-24$ \\
\hline
\end{tabular}

Batch sorption experiments for $\mathrm{Cd}(\mathrm{II})$ retention onto silver fir bark were performed according to the procedure presented in Fig. 1. The absorbance measurements were performed using a 210 VGB Buck Scientific atomic absorption spectrometer.

The effects of the experimental parameters such as $\mathrm{pH}$, sorbent dose, metal concentration, temperature and contact time on the $\mathrm{Cd}$ (II) sorption by silver fir bark are systematized in Table 1. Each experiment was carried out by varying the parameter under study and maintaining the other parameters constant.

All the experiments were carried out in triplicate and the average of the values were used for the further calculation.

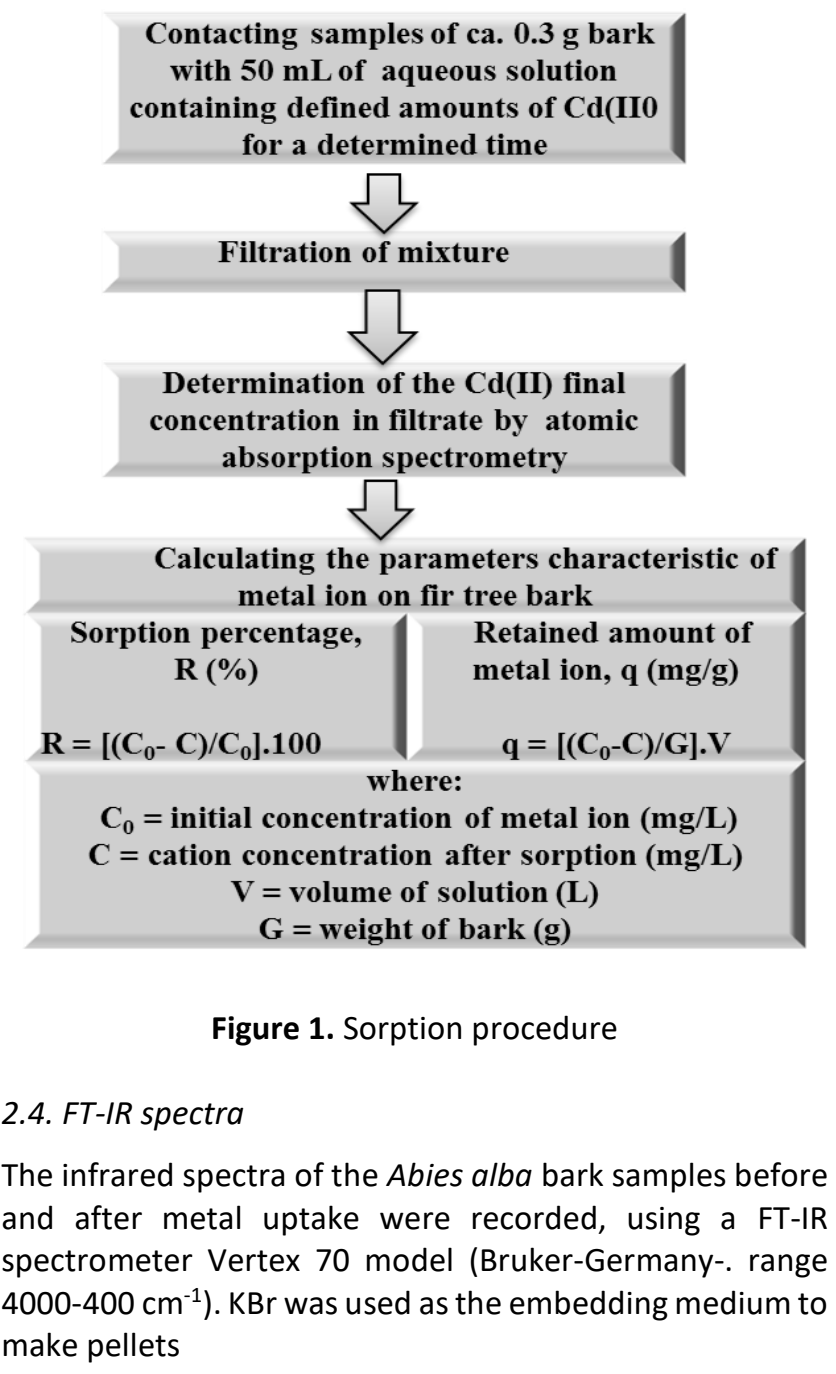

Contacting samples of ca. $0.3 \mathrm{~g}$ bark with $50 \mathrm{~mL}$ of aqueous solution for a determined time

Determination of the Cd(II) final centration in filtrate by atomic \

Calculating the parameters characteristic of metal ion on fir tree bark

\begin{tabular}{|c|c|}
\hline $\begin{array}{c}\text { Sorption percentage, } \\
\text { R }(\%)\end{array}$ & $\begin{array}{l}\text { Retained amount of } \\
\text { metal ion, } q(\mathrm{mg} / \mathrm{g})\end{array}$ \\
\hline$R=\left[\left(C_{0^{-}} C\right) / C_{0}\right] .100$ & $q=\left[\left(C_{0}-C\right) / G\right] \cdot V$ \\
\hline \multicolumn{2}{|c|}{$\begin{array}{l}\text { where: } \\
\begin{array}{r}\mathrm{C}_{0}=\text { initial concentration of metal ion }(\mathrm{mg} / \mathrm{L}) \\
\mathrm{C}=\text { cation concentration after sorption }(\mathrm{mg} / \mathrm{L}) \\
\mathrm{V}=\text { volume of solution }(\mathrm{L}) \\
\mathbf{G}=\text { weight of bark }(\mathrm{g})\end{array}\end{array}$} \\
\hline
\end{tabular}

Figure 1. Sorption procedure

\subsection{FT-IR spectra}

The infrared spectra of the Abies alba bark samples before and after metal uptake were recorded, using a FT-IR spectrometer Vertex 70 model (Bruker-Germany-. range make pellets 


\section{Results and Discussion}

\subsection{Characterization of the silver fir bark}

Previous studies showed that the major chemical components of the raw Abies alba bark are cellulose (48.24-58.32\%) and lignin (29.20-33.30\%) (Nagy et al., 2013). Their presence in the bark structure is responsible for the sorptive capabilities of this material.

Bark components offer a large variety of functional groups that are able to bind metals through chemical interactions (Fig.2). The most important bands of the silver fir bark and Cd-loaded silver fir bark with the respective assignments are:

- $3600-3200 \mathrm{~cm}^{-1}$ - corresponding to the deformation of $\mathrm{O}-\mathrm{H}$ and $\mathrm{N}-\mathrm{H}$ groups present in alcohols and phenols;

- $2950-2800 \mathrm{~cm}^{-1}$ - attributed to $\mathrm{C}-\mathrm{H}$ asymmetrical and symmetrical stretching;

- 1650-1500 $\mathrm{cm}^{-1}$ - Represents the stretching vibration of $\mathrm{C}=\mathrm{O}$ bonds, which originates from non-ionic carboxyl groups $\left(-\mathrm{COOH},-\mathrm{COOCH}_{3}\right)$, and may be denoted by carboxylic acids or corresponding esters.

- $\quad 1330-900 \mathrm{~cm}^{-1}$ - This band can be connected to the existence of stretching vibrations of $\mathrm{C}-\mathrm{O}$ from phenolic groups.

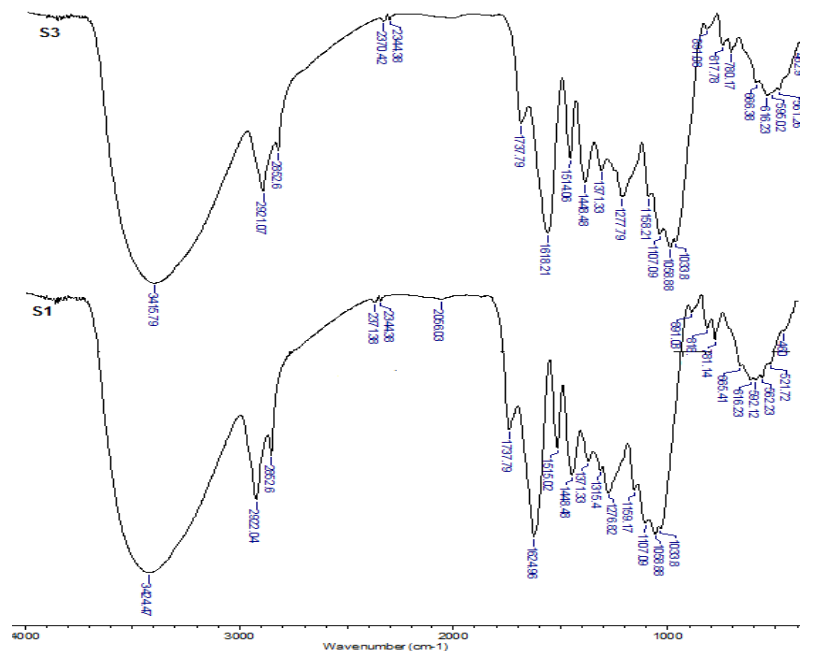

Figure 2. IR-spectra for: S1- silver fir bark; S3- silver fir bark-Cd(II) ions

\subsection{Batch studies}

\subsubsection{Effect of initial $\mathrm{pH}$ on the $\mathrm{Cd}(\mathrm{II})$ retention by silver fir} bark

The initial pH plays a vital role in the removal of cadmium ions from wastewaters by sorption due to its impact on both the surface functional groups of sorbents and the metal chemistry in water (Salman et al., 2016). The effect of initial $\mathrm{pH}$ on the removal efficiency of $\mathrm{Cd}$ (II) by using wastes of Romanian silver fir bark was studied at different $\mathrm{pH}$ ranging from 1.0 to 5.0. It must be emphasized that the double positively charged ionic form of cadmium is predominant at initial $\mathrm{pH}=1-5$ (Bayat, 2002) The $\mathrm{pH}$ sorption profile is shown in Fig 3.

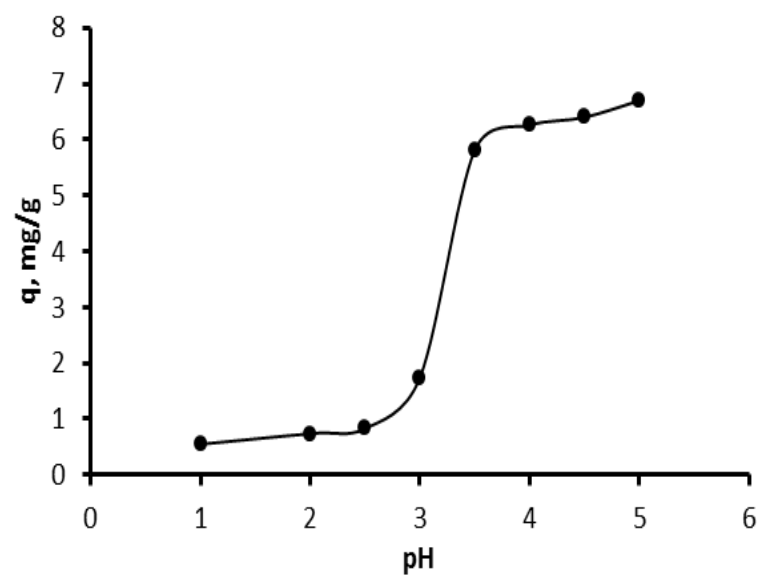

Figure 3. The influence of initial $\mathrm{pH}$ on the $\mathrm{Cd}(\mathrm{II})$ ions retention by Abies alba bark

It was observed that a sharp increase in the $\mathrm{Cd}$ (II) sorption ability of the Abies alba bark occurred when the $\mathrm{pH}$ of the initial solutions changed from 1 to 3.5 and after 3.5 a plateau is obtained. The explanation for the low $\mathrm{Cd}$ (II) sorption at strong acidic medium may be the electrostatic repulsion between the positive net charge on the Abies alba bark (as the result of its pronounced protonation) and the positively charged cadmium ions (Tofan et al., 2012). The increased sorption of Cd(II) on Abies alba bark at higher values of initial $\mathrm{pH}$ may be due to the ionization of functional groups and the increase in the negative charge density on the bark surface which significantly improved the attraction of the tested cations (Amalinei et al., 2012).

In this context, the influence of bark dose, $\mathrm{Cd}(\mathrm{II})$ initial concentration, temperature and contact time was performed with solutions of initial $\mathrm{pH} 4.5-5$. This finding is in good agreement with literature data reporting that the metal sorption on barks normally occurs under slightly acidic conditions (Sen, 2015).

\subsubsection{Effect of bark dose}

The influence of silver fir bark dose on the sorption of Cd(II) is illustrated in Fig 4. It was observed that the $\mathrm{Cd}(\mathrm{II})$ removal efficiency increased rapidly from $32 \%$ to $87.8 \%$ with increasing of the bark concentration from $3 \mathrm{~g} \mathrm{l}^{-1}$ from 20 $\mathrm{gl}^{-1}$. This trend can be attributed to the increase in surface area resulting from the increase in sorbent mass, thus increasing the number of active sorption sites (Nguyen et al., 2013). At higher sorbent dose, the equilibrium sorption of $\mathrm{Cd}(\mathrm{II})$ ions did not increase significantly with the increasing of the bark dose from 20 to $30 \mathrm{~g} \mathrm{l}^{-1}$. This behavior is expected due to the saturation level attained during the sorption process (Safiur Rahman and Rafiqul Islam, 2009).

\subsubsection{Effect of $C d(I I)$ concentration in initial solutions}

The influence of metal ion initial concentration on $\mathrm{Cd}(\mathrm{II})$ biosorption by Abies alba bark is shown in Table 2. It can be seen from Table 2 that the amount of $\mathrm{Cd}$ (II) ions retained on the tested silver fir bark (q) increased with increasing 
metal ion concentration. Conversely, the increase of initial metal concentration leads to the decrease of the removal efficiency ( $R \%)$. The increasing trend may be attributed to the increase in the driving force of the $\mathrm{Cd}$ (II) concentration gradient produced by the increase in the initial metal ion concentration.

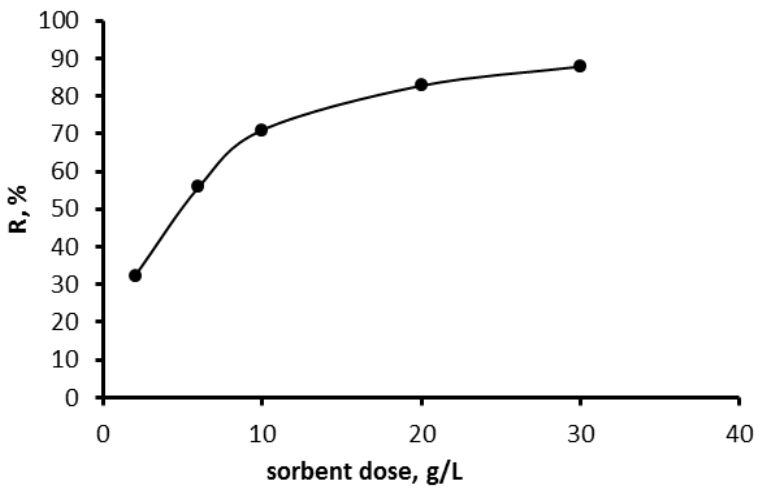

Figure 4. The effect of sorbent dose on the $\mathrm{Cd}(\mathrm{II})$ ions uptake by Abies alba bark

The lower removal efficiencies at higher $\mathrm{Cd}$ (II) initial concentrations might be closely associated with insufficient binding sites for sorption or to the saturation of the binding sites (Arief et al., 2008). On the basis of this behavior it can be concluded that the wastes of Romanian silver fir bark may be a sustainable material for the efficient removal of $\mathrm{Cd}$ (II) from industrial effluents with low content in the tested cation.

Table 2. Effect of initial concentration ( $\left.\mathrm{C}_{0}\right)$ on $\mathrm{Cd}(\mathrm{II})$ sorption by Abies alba bark

\begin{tabular}{ccc}
\hline Initial concentration $\mathbf{C}_{\mathbf{0}}, \mathbf{~ m g ~ l}^{\mathbf{1}}$ & $\mathbf{q}, \mathbf{~ m ~ g ~}^{-\mathbf{1}}$ & $\mathbf{R}, \mathbf{\%}$ \\
\hline 24.00 & 3.11 & 80.00 \\
\hline 48.00 & 5.26 & 77.86 \\
\hline 72.00 & 6.69 & 71.25 \\
\hline 96.00 & 7.06 & 65.83 \\
\hline 120.00 & 8.72 & 59.20 \\
\hline 144.00 & 10.91 & 52.00 \\
\hline 168.00 & 13.16 & 48.70 \\
\hline 192.00 & 15.58 & 45.50 \\
\hline
\end{tabular}

\subsubsection{Isotherms of $\mathrm{Cd}(\mathrm{II})$ sorption}

The sorption isotherms help in designing sorption process systems, since equilibrium studies determine the sorption capacities of the low - cost sorbents. In order to come up with an optimum design for successful sorptive removal of heavy metal ions from wastewaters it is imperative to establish the best correlation for the equilibrium isotherms (Moyo et al., 2015). In present study, the equilibrium data obtained for $\mathrm{Cd}(\mathrm{II})$ removal using wastes of Abies alba bark were interpreted by means of two parameters isotherm models, Langmuir and Freundlich.

The Langmuir model is based on the reaction hypotheses and assumes monolayer sorption on a finite number localized sites that are equivalent with no lateral interaction and steric hindrance between the sorbed species, even on adjacent sites. Homogeneous sorption occurs with each molecule possessing constant enthalpies and sorption activation energy without transmigration of the sorbate in the plane of the surface (Febrianto et al., 2009). Fig. 5 shows the Langmuir isotherms for $\mathrm{Cd}$ (II) ions sorption on the investigated silver fir bark at three different temperatures. The $\mathrm{Cd}(\mathrm{II})$ ions sorption on the Abies alba bark under study is characterized in Table 3 by means of Langmuir constants obtained from the corresponding linear Langmuir plots.

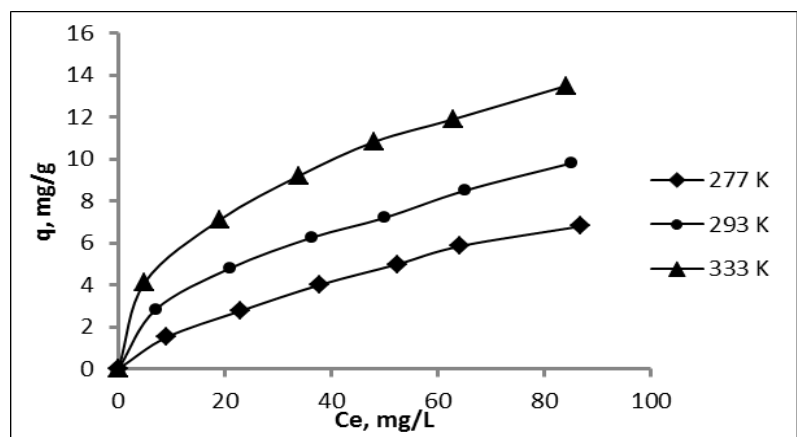

Figure 5. Langmuir isotherms of $\mathrm{Cd}(\mathrm{II})$ ions sorption on silver tree bark

The high values of $K_{L}$ in Table 3 confirmed that the sorption of $\mathrm{Cd}$ (II) on Romanian silver fir tree bark was a favorable process. The maximum capacity of Abies alba bark for the uptake of $\mathrm{Cd}(\mathrm{II})$, derived from the application of Langmuir equation was $11.98 \mathrm{mg} \mathrm{g}^{-1}$ at $20{ }^{\circ} \mathrm{C}$ in this work. This value for Romanian silver tree bark sorption capacity of $\mathrm{Cd}$ (II) was higher than other reported values for various barks, as summarized in Table 4. Although not being best of all, the Abies alba bark can be regarded as a good sorbent candidate in decontamination of waters containing $\mathrm{Cd}(\mathrm{II})$.

Freundlich isotherm describes the non-ideal and reversible multilayer sorption, with non uniform distribution of sorption heat and affinities over the heterogeneous surface (Manohar et al., 2002). The stronger binding sites are occupied first, until sorption energies are exponentially decreased upon the completion of sorption process. The empirical values of the Freundlich constants at three different temperatures for $\mathrm{Cd}$ (II) ion-silver fir tree bark batch sorption system are recorded in Table 3. The $n$ values are above unity, indicating favorable sorption of the $\mathrm{Cd}$ (II) ions by Abies alba bark under study at all working temperatures. The $K_{F}$ values determined in this study are significantly higher than those determined in previous studies using other low-cost sorbents such as Tamrix articulata wastes or bottlebrush seeds (Al Othman et al., 2010; Rao and Kashiffudin, 2014).

To compare the Langmuir and Freundlich isotherm models, the experimental data were statistically processed by linear regression. High values of the linear regression correlation coefficients $\left(R^{2}\right)$ for both Langmuir and Freundlich plots (Table 3 ) suggest that monolayer sorption, as well as heterogeneous surface conditions may co-exist under applied experimental conditions. A similar behavior has been reported in the literature for the sorption of $\mathrm{Cu}(\mathrm{II})$ and $\mathrm{Zn}$ (II) ions on Romanian Pinus sylvestris L bark (Amalinei et al., 2012). 
Table 3. Isotherm parameters

\begin{tabular}{|c|c|c|c|c|c|}
\hline \multicolumn{6}{|c|}{ Langmuir isotherm (Langmuir, 1916) } \\
\hline \multirow{2}{*}{ Equation } & \multicolumn{4}{|c|}{ Quantitative parameters } & \multirow{2}{*}{ Isotherm parameters, significance } \\
\hline & $\mathrm{T}, \mathrm{K}$ & $\mathrm{K}_{\mathrm{L}}, \mathrm{L} \mathrm{mol}^{-1}$ & $q_{0}, \mathrm{mg} \mathrm{g}^{-1}$ & $\mathbf{R}^{\mathbf{2}}$ & \\
\hline \multirow{3}{*}{$q=K_{L} \cdot C \cdot q_{0} /\left(1+K_{L} \cdot C\right)$} & 277 & 1543.20 & 11.76 & 0.9945 & \multirow{3}{*}{$\begin{array}{c}\mathrm{K}_{\mathrm{L}}-\text { binding energy } \\
\text { (relative sorption affinity) } \\
\text { qo maximum capacity of sorption }\end{array}$} \\
\hline & 293 & 3597.12 & 11.98 & 0.9904 & \\
\hline & 333 & 8403.36 & 13.10 & 0.9927 & \\
\hline \multicolumn{6}{|c|}{ Freundlich isotherm (Freundlich, 1906) } \\
\hline \multirow[t]{2}{*}{ Equation } & \multicolumn{4}{|c|}{ Quantitative parameters } & Isotherm parameters, significance \\
\hline & & $K_{F}$ & $\mathbf{n}$ & $\mathbf{R}^{2}$ & \multirow{4}{*}{$\begin{array}{l}\text { KF- sorption capacity } \\
\text { n-energy of sorption }\end{array}$} \\
\hline \multirow{3}{*}{$\begin{array}{c}\log q=\log K_{F}+(1 / n) \log C \\
\text { (linearised form) }\end{array}$} & 277 & 0.327 & 1.458 & 0.9989 & \\
\hline & 293 & 1.071 & 2.023 & 0.9970 & \\
\hline & 333 & 2.063 & 2.354 & 0.9996 & \\
\hline
\end{tabular}

Table 4. Comparison of sorption capacity of various tree barks for $\mathrm{Cd}(\mathrm{II})$ from aqueous solution

\begin{tabular}{|c|c|c|}
\hline Sorbent & Maximum Cd(II) sorption capacity, $\mathbf{~ m g ~}^{-1}$ & Reference \\
\hline Abies sachalinensis bark & 6.72 & (Seki et al., 1997) \\
\hline Pinus pinaster bark & 7.84 & (Kumar, 2006) \\
\hline Juniperus monosperma bark & 10.08 & (Shin et al., 2007) \\
\hline Ceratonia siliqua bark & 14.27 & (Farhan et al., 2012) \\
\hline Bark of Eucalyptus (globulus) & 14.56 & (Tofan et al., 2012) \\
\hline Romanian Pinus sylvestris L. Bark & 27.32 & (Salem et. al, 2012) \\
\hline Eriobotrya japonica Loquat bark & 28.80 & (Seki et al., 1997) \\
\hline Harwickia binata bark & 33.60 & (John et al., 2011) \\
\hline Cassia siamea bark & 37.70 & This study \\
\hline
\end{tabular}

\subsubsection{Effect of temperature and thermodynamic parameters}

It is obvious from Fig. 5 and Table 5 that the temperature has a favorable effect within the sorption system under study. Both Langmuir and Freundlich constants (Table 3) increase with increasing temperature, showing that the sorption capacity and the intensity of sorption are enhanced at higher temperatures. This behavior may be attributed to either increase in the number of active sites present on the surface of the sorbent or the increase in the attractive forces between the metal ions and the sorbent (Yuvaraja et al., 2014)

The thermodynamic parameters, free energy change $(\Delta G)$, enthalpy change $(\Delta H)$ and entropy change $(\Delta S)$ were calculated on the basis of Langmuir constant $K_{L}$ at different temperatures by using the equations recorded in Table 5.

Table 5. The thermodynamic parameters of the sorption process of Cd(II) ions on Romanian Abies alba bark

\begin{tabular}{|c|c|c|c|}
\hline Thermodynamic parameter & Equations (Khazali et al., 2007) & $\mathrm{T}, \mathrm{K}$ & Obtained values \\
\hline \multirow{3}{*}{ Free energy change, $\Delta \mathrm{G},\left(\mathrm{kJ} \mathrm{mol}^{-1}\right)$} & $\Delta \mathrm{G}=-\mathrm{RT} \ln \mathrm{K}_{\mathrm{L}}$ & 277 & $-\quad 16.520$ \\
\hline & \multirow{2}{*}{$\begin{array}{l}\mathrm{R} \text { is the gas constant; } \\
\mathrm{T} \text { is the absolute temperature }\end{array}$} & 293 & 19.910 \\
\hline & & 333 & 25.004 \\
\hline \multirow{3}{*}{ Enthalpy change, $(\Delta \mathrm{H}), \mathrm{kJ} \mathrm{mol}^{-1}$} & \multirow{3}{*}{ In $K_{L}=$ constant $=-\frac{\Delta H}{R T}$} & 277 & \multirow{3}{*}{21.90} \\
\hline & & 293 & \\
\hline & & 333 & \\
\hline \multirow{3}{*}{ Entropy change $(\Delta S), \mathrm{kJ} \mathrm{mol}^{-1}$} & \multirow{3}{*}{$\Delta S=\frac{\Delta \mathrm{H}-\Delta \mathrm{G}}{\mathrm{T}}$} & 277 & 0.1380 \\
\hline & & 293 & 0.1420 \\
\hline & & 333 & 0.1400 \\
\hline
\end{tabular}

The negative values of $\Delta \mathrm{G}$ in Table 5 suggest that the sorption of $\mathrm{Cd}(\mathrm{II})$ on Romanian Abies alba bark is a spontaneous process and thermodynamically favorable under the experimental conditions. Furthermore, the decrease in the values of $\Delta \mathrm{G}$ reflects that the $\mathrm{Cd}(\mathrm{II})$ sorption process is more spontaneous at higher temperatures (Chen et al., 2010). The positive value of $\Delta H$ suggests that the process of $\mathrm{Cd}(\mathrm{II})$ sorption on the bark under study is endothermic. On the basis of the positive value of $\Delta S$ in
Table 5 it can be concluded that the process is entropy driven and with an increased randomness at the bark/ solution interface during the sorption of $\mathrm{Cd}(\mathrm{II})$ on the Romanian Abies alba bark

\subsubsection{Effect of contact time}

The kinetic data for the sorption of Cd(II) ions by Romanian silver fir tree bark are plotted in Figure 6. 


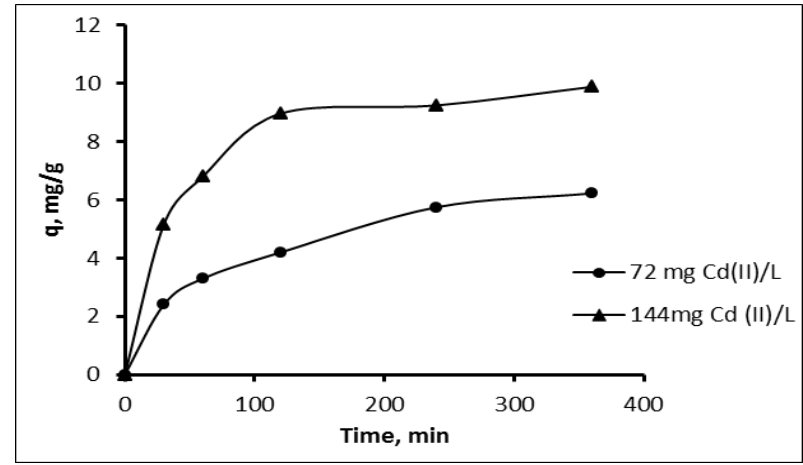

Figure 6. Effect of the contact time on $\mathrm{Cd}$ (II) ions retention by silver fir tree bark.

As shown in Figure 6, the removal rate of $\mathrm{Cd}$ (II) was rapid at the beginning and it became slow with increase of the contact time. It was observed that the process of $\mathrm{Cd}(\mathrm{II})$ sorption on Romanian Abies alba bark reached equilibrium at 120 minutes. It was showed no significant changes on silver fir tree bark with a further increasing contact time. The rapid uptake of $\mathrm{Cd}$ (II) ions at the initial period may be due to the availability of vacant sorption sites on the surface of the sorbent. The sorption process became slow later owing to the decrease of available sorption sites (Wang et al., 2010).

\subsubsection{Kinetic modeling}

Table 6. Kinetic description of the Cd(II)- Romanian Abies alba bark sorption system

\begin{tabular}{|c|c|c|c|}
\hline \multicolumn{2}{|c|}{$\mathrm{C}_{0}, \mathrm{mgCd}(\mathrm{II}) \mathrm{I}^{-1}$} & \multirow{2}{*}{$\begin{array}{c}72.00 \\
6.67 \cdot 10^{-3}\end{array}$} & \multirow{2}{*}{$\frac{144.00}{7.13 \cdot 10^{-3}}$} \\
\hline Pseudo-first-order & $\mathbf{k}_{1},\left(\min ^{-1}\right)$ & & \\
\hline kinetics & $\mathbf{R}^{2}$ & 0.9890 & 0.9874 \\
\hline \multirow{4}{*}{$\begin{array}{l}\text { Pseudo-second-order } \\
\text { kinetics }\end{array}$} & $\mathbf{k}_{2,}\left(\mathrm{~g} \mathrm{mg}^{-1} \mathrm{~min}^{-1}\right)$ & $1.75 \cdot 10^{-3}$ & $2.99 \cdot 10^{-3}$ \\
\hline & h, $\left(\mathrm{g} \mathrm{mg}^{-1} \mathrm{~min}^{-1}\right)$ & 0.0986 & 0.3420 \\
\hline & $q_{0}\left(g g^{-1}\right)$ & 7.49 & 10.69 \\
\hline & $\mathbf{R}^{2}$ & 0.9934 & 0.9984 \\
\hline
\end{tabular}

The pseudo-second-order kinetic model implies that the rate of sorption sites covering is proportional to the square of the number of unoccupied and occupied sites (Ho, 2006). This model is based on the following equation (Ho and Mckay, 1999):

$$
1 / q_{t}=1 / h+\left(1 / q_{e}\right) \cdot t
$$

where $k_{2}$ is the rate constant of the pseudo-second-order model and $h=k_{2} \cdot q_{e}^{2}\left(\mathrm{mg} \mathrm{g}^{-1} \mathrm{~min}^{-1}\right)$ can be regarded as the initial sorption rate constant of the pseudo-second-order sorption $\left(\mathrm{g} \mathrm{mg}^{-1} \mathrm{~min}^{-1}\right)$.

According to this model, it can be assumed that one cadmium ion is sorbed onto two sorption sites on the bark surface

$$
2 \mathrm{~A}+\mathrm{Cd}^{2+} \stackrel{k_{2}}{\longrightarrow} \mathrm{A}_{2} \mathrm{Cd} \text { solid phase }
$$

where $A$ represents an unoccupied sorption site on the silver fir bark and $k_{2}$ is the pseudo-first-order rate constant.

The kinetic parameters derived from the plots of the linearized form of the pseudo-second-order equation are recorded in Table 6, along with the corresponding correlation coefficients. As shown in Table 6 , the $R^{2}$ are very
Kinetics of sorption is one of the most important characteristics to be responsible for the efficiency of sorption (Mihailescu et al., 2012). Kinetic studies gave detailed information on the mechanism of sorption and potential rate controlling steps. Kinetics of $\mathrm{Cd}$ (II) retention on the Abies alba bark under study was modeled by means of pseudo-first-order and pseudo-second-order kinetic models.

The pseudo-first-order model (Lagergren's equation) describes adsorption in solid-liquid systems based on the sorption capacity of solids (Ho, 2004). On the basis of this model one can assumes that one cadmium ion is sorbed onto one sorption site on the silver fir tree bark surface:

$$
\mathrm{A}+\mathrm{Cd}^{2+} \stackrel{k_{1}}{\longrightarrow} \mathrm{ACd} \text { solid phase }
$$

where $A$ represents an unoccupied sorption site on the bark and $k_{1}$ is the pseudo- first-order rate constant $\left(\mathrm{min}^{-1}\right)$.

The Lagergren pseudo-first-order kinetic model is represented by the following equation (Lagergren, 1898):

$$
\log \left(q_{e}-q_{t}\right)=\log q_{e}-k_{1} . t / 2.303
$$

The kinetic parameters obtained from the linear Lagergren plots for this study are given in Table 6, together with the corresponding determination coefficients $\left(R^{2}\right)$. The $R^{2}$ values are less, suggesting that the sorption of $\mathrm{Cd}$ (II) on the bark under study does not follows pseudo-first-order model. close to unity (0.99) for both $\mathrm{Cd}(\mathrm{II})$ concentrations, indicating the applicability of the pseudo-second order kinetic model to the sorption of $\mathrm{Cd}$ (II) on the Romanian Abies alba bark. According to literature data, the pseudosecond order kinetic model includes different sorption mechanisms such as surface complexation or ion exchange. The model is based on the assumption that the ratelimiting step is the chemisorption (Yuvaraja et al., 2014). Furthermore, the sorption rate depends on the concentration of $\mathrm{Cd}(\mathrm{II})$ ions on the Abies alba bark surface (Table 6).

\section{Conclusions}

Romanian Abies alba bark - a low cost and abundant forest by - product - could act as potential sorbent for the removal of $\mathrm{Cd}(\mathrm{II})$ ions from wastewaters. The optimum value of initial $\mathrm{pH}$ for $\mathrm{Cd}(\mathrm{II})$ ions sorption was found to be 4.5 to 5 . The $\mathrm{Cd}(\mathrm{II})$ removal efficiency increased rapidly from $32 \%$ to $87.8 \%$ with increasing of silver fir tree bark concentration from $3 \mathrm{~g} \mathrm{l}^{-1}$ from $20 \mathrm{~g} \mathrm{l}^{-1}$. The amount of $\mathrm{Cd}$ (II) retained on the bark under study under increased with the increasing of metal ion concentration, while the $\mathrm{Cd}(\mathrm{II})$ 
sorption percentage decreased. The sorption isotherm studies clearly indicated that the sorptive behavior of $\mathrm{Cd}$ (II) ions on Romanian Abies alba bark under study satisfies not only the Langmuir assumptions, but also the Freundlich assumption. The calculated values for the isothermal thermodynamic parameters show that $\mathrm{Cd}$ (II) ions retention by silver fir tree bark is a spontaneous process of endothermic and chemical nature. The sorption kinetics for $\mathrm{Cd}(\mathrm{II})$ ions removal from aqueous solutions with initial $\mathrm{pH}$ of 4.5 to 5 was very well described by pseudo-second order model.

\section{References}

Al - Asheh S. and Duvnyak Z. (1997), Sorption of cadmium and other heavy metals by pine bark, Journal of Hazardous Materials, 56, 35-51.

Al Othman Z.A., Hashem A. and Habila M.A. (2011), Kinetic, equilibrium and thermodynamic studies of cadmium(II) adsorption by modified agricultural waste, Molecules, 16, 10443-10454.

Amălinei R.L., Miron A., Volf I., Păduraru C. and Tofan L. (2012), Investigations on the feasibility of Romanian pine bark wastes conversion into a value - added sorbent for $\mathrm{CU}$ (II) and $\mathrm{Zn}$ (II) ions, BioResources, 7, 148-160.

Aoyama M., Kishino M. and Jo T.S. (2004), Biosorption of $\mathrm{Cr}(\mathrm{VI})$ on Japanese cedar bark, Separation Science and Technology, 39, 1149-1162.

Arief V.O., Trilestari K., Sunarso J., Indraswati N. and Ismadji S. (2008), Recent progress on biosorption of heavy metals from liquids using low - cost biosorbents., Clean, 36, 937 - 962.

Bayat B. (2002), Combined removal of zinc(II) and cadmium(II) from aqueous solutions by adsorption onto high-calcium Turkish fly ash, Water, Air and Soil Pollution, 136, 66-92.

Chen H., Zhao J., Dai G.L., Wu Y.H. and Yan H.(2010), Adsorption characteristics of $\mathrm{Pb}$ (II) from aqueous solution onto natural biosorbent, fallen Cinnamomum camphora leaves, Desalination, 262, 174-182.

Escudero C.F., Fiol N., Poch J. and Villaescusa I. (2008), The kinetics of copper sorption onto yohimbe bark wastes, International Journal of Environment and Pollution,34, 215-230.

Farhan A.M., Salem N.M., Ahmad A.L. and Awwad A.M. (2012), Kinetic, equilibrium and thermodynamic studies on the biosorption of heavy metals by Ceratonia siliqua bark, American Journal of Chemistry, 2, 335-342.

Febrianto J., Kosasih A.N., Sunarso, J., Ju J.H., Indraswati N. and Ismadji S. (2009), Equilibrium and kinetic studies in adsorption of heavy metals using biosorbent: a summary of recent studies, Journal of Hazardous Materials, 162, 616-645.

Freundlich H.M.F. (1906), Over the adsorption in solution, Journal of Physical Chemistry, 57, 385-470

Gondogdu A., Ozdes D., Duran C., Bulit V.N., Soylak M. and Senturk H.B. (2009), Biosorption of $\mathrm{Pb}$ (II) ions from aqueous solution by pine bark (Pinus brutia Ten.), Chemical Engineering Journal, 153, 62 - 69.

Ghodbane I., Nouri. K., Hamdaoui O. and Chiha M. (2008), Kinetic and equilibrium study for the sorption of cadmium (II) ions from aqueous phase by eucalyptus bark, Journal of Hazardous Materials, 152, 148-158

Ghosh D., Saha R., Ghosh A., Nandi R. and Saha B. (2015), A review on toxic cadmium biosorption from contaminated wastewater, Desalination and Water Treatment, 53, 413-420.
Ho Y.S. (2004), Citation review of Lagergren kinetic rate equation on adsorption reactions, Scientometrics, 59, 171-177.

Ho Y.S. (2006), Review of second-order models for adsorption systems, Journal of Hazardous Materials, 136, 681-689.

Ho Y.S. and McKay G. (1999), Pseudo-second order for the sorption process, Biochemistry, 34, 451-456.

Jauberty L., Gloaguen V., Asher C., Krausz P., Delpech V., Berland A., Grauger V., Niort I., Royer A. and Decossas J.L. (2011), Bark, a suitable biosorbent for the removal of uranium from waste water - From laboratory to industry, Radioprotection, 46, 443-456.

John A.C., Ibironke L.O., Adedeji V. and Oladunni O. (2011), Equilibrium and kinetic studies of the biosorption of heavy metals (cadmium) on Cassia siamea bark, American Eurasian Journal of Scientific Research, 6, $123-130$

Khazali O., Abu-El-Halawa R. and Sou Vod, K.A. (2007), Removal of copper(II) from aqueous solution by Jordanian pottery materials, Journal of Hazardous Materials, 139, 67-71.

Kumar U. (2006), Agricultural products and by-products as a lowcost adsorbent for heavy metal removal from water and waste-water: a review, Scientific Research and Essays, 1, 33-37

Lagergren S. (1898), About the theory of so-called adsorption of solid substance, Handlinger, 24, 1-39.

Langmuir I. (1916), The adsorption of gases on plane surface of glass, mica and platinum, Journal of the American Chemical Society, 40, 1361-1368.

Manohar D.M., Krishnan A.K. and Anirudhan T.S. (2002), Removal of mercury from aqueous solutions and chlor-alkali industry wastewater using 2- mercaptobenzimidazole, Water Research, 36, $1609-1619$

Manzatu C., Nagy B., Torok A., Indolean C. and Majdik C. (2014), Biosorption of $\mathrm{Cd}(\mathrm{II})$ on untreated fir cone powder: Kinetic and equilibrium isotherm studies, Revue Roumaine de Chimie, 60, $263-273$.

Moyo M., Guyo U., Mawenyiyo G., Zinyama N.P. and Nyamunda B.C. (2015), Marula seed husk( Sclerocarya birrea)biomass as a low -cost biosorbent for removal of $\mathrm{Pb}$ (II) and $\mathrm{Cu}(\mathrm{II})$ from aqueous solution, Journal of Industrial and Engineering Chemistry, 27, 126- 132.

Nagy B., Maicaneanu A., Indolean C., Burca S., Silaghi-Dumitrescu L. and Majdik C. (2013), Cadmium(II) removal from aqueous solution using Romanian untreated fir tree sawdust - a green biosorbent, Acta Chemica Slovenica, 60, $263-273$.

Nguyen T.A.H., Ngo H.H., Guo W.S., Zhang J., Liang S., Yue Q.Y., Li Q. and Nguyen T.V. (2013), Applicability of agricultural wastes and by-products for adsorptive removal of heavy metals from wastewater, Bioresource Technology ,148, 574-585.

Okoro I.A. and Okoro S.A. (2011), Agricultural by-products as green chemistry adsorbents for the removal and recovery of metal ions from waste- water environments, Continental Journal of Water, Air and Soil Pollution, 2, 15-22.

Purkaystha D., Mishra U. and Biswas S. (2014), A comprehensive review on Cd(II) removal from aqueous solutions, Journal of Water Process Engineering, 2, 105-128.

Rao K.S., Mohapatra M., Anand S. and Venkateswarlu P. (2010), Review on cadmium removal from aqueous solutions, International Journal of Engineering Science and Technology, 2, 81- 123.

Rao R.A. and Kashiffudin M. (2014), Kinetic and isotherm studies of $\mathrm{Cd}(\mathrm{II})$ adsorption from aqueous solution using seeds of 
bottlebrush plant (Callistemon chisholma), Applied Water Science, 4, 371-383.

Salem N.M., Awwad A.M. and Al-Dujahi Ammar H. (2012), Biosorption of $\mathrm{Pb}(\mathrm{II}), \mathrm{Zn}(\mathrm{II})$ and $\mathrm{Cd}(\mathrm{II})$ by Eriobotrya japonica Loquat bark, International Journal of Environmental Protection, 2, 1-7.

Safiur Rahman M. and Rafiqul Islam M. (2009), Effects of pH on isotherms modeling for $\mathrm{Cu}(\mathrm{II})$ adsorption using maple wood sawdust, Chemical Engineering Journal, 149, 273-280.

Salman T., Temel F.A., Turan N.G. and Ardali Y. (2016), Adsorption of lead(II) ions onto diatomite from aqueous solutions: mechanism, isotherm and kinetic studies, Global NEST Journal, 2016, 1-10.

Seki K., Saito N. and Aoyama M. (1997), Removal of heavy metal ions from solutions by coniferous barks, Wood Science and Technology, 31, 441-447.

Sen A., Perreira H., Olivella M.A. and Villaescusa I. (2015), Heavy metals removal in aqueous environments using bark as a biosorbent, International Journal of Environmental Science and Technology, 12, 391-414.

Shin E.W., Karthikeyan K.G. and Tshabalala M.A. (2007), Adsorption mechanism of cadmium on juniper bark and wood, Bioresource Technology, 98, 588-594.

Teodosiu C., Wenkert R., Tofan L. and Păduraru C. (2014), Advances in preconcentration/removal of environmentally relevant heavy metal ions from water and wastewaters by sorbents based on polyurethane foam, Reviews in Chemical Engineering, 30, $403-420$.

Tofan L., Paduraru C., Robu B., Miron A. and Mihăilescu Amălinei R.L. (2012), Removal of Cd(II) ions from aqueous solution by retention on pine bark, Environmental Engineering and Management Journal, 11, 199-205.

Volenski B. (2001), Detoxification of metal - bearing effluents: biosorption for the next century, Hydrometallurgy, 59, 203-216.

Wang F.Y., Wang H and Ma J.W. (2010), Adsorption of cadmium(II) from aqueous solution by a new low-cost adsorbent- bamboo charcoal, Journal of Hazardous Materials, 177, 300 - 306.

Yuvaraja G., Krishnaiah N., Subbaiah M.V. and Krishnaiah A. (2014), Biosorption of $\mathrm{Pb}(\mathrm{II})$ from aqueous solution by Solanum melongena leaf powder as a low-cost biosorbent prepared from agricultural waste, Colloids and Surfaces $B$ : Biointerfaces, 114, $75-81$ 